\title{
РАЗРАБОТКА ИНТЕЛЛЕКТУАЛЬНОЙ ИНФОРМАЦИОННОЙ СИСТЕМЫ ДЛЯ ВЫРАЩИВАНИЯ ЧАЙНЫХ ПЛАНТАЦИЙ ПРИГОРНЫХ РЕГИОНАХ
}

\author{
(c) 2021 Д. Ф. оглу Мамедов ${ }^{1}$, Р. О. гызы Нариманова ${ }^{1}$, Г. Ю. гызы Аббасова ${ }^{1}$, \\ О. И. Попова ${ }^{\bowtie 2}$, М. И. Попова ${ }^{2}$ \\ ${ }^{1}$ Сумгаитский государственный университет \\ 43-й квартал, 1-й корпус, Сумгаит, AZ 5008 \\ ${ }^{2}$ Воронежский государственный технический университет \\ ул. 20-летия Октября, 84, 394006 Воронеж, Российская Федераиия
}

\begin{abstract}
Аннотация. На основе проведенного сравнительного анализа проблемы и исследования по разработке интеллектуальных информационных систем для выращивания сельскохозяйственных растений (на примере чайных плантаций), поставлена цель работы. Целью статьи является создание интеллектуальной информационной системы контроля и управления процессом выращивания чайной плантации, обеспечивающей эффективное использование водных ресурсов, выбор видов полива чайных кустов и автоматизацию процесса мелиорации и агротехнических работ в зависимости от метеорологических, геофизических и биологических данных чайного растения. Проведя сравнительный анализ статистических метеорологических данных мировых производителей чая Азербайджана, была построена сравнительная диаграмма средних метеорологических показателей этих стран и определены основные требования необходимых показателей: температуры, относительной влажности воздуха, солнечных дней, скорости ветра для выращивания чайных плантаций, что способствовало бы повышению производительности и качеству чайных листьев. В соответствии с методами посадки чайных плантаций на неровных участках мировых чайных производителей на примере Индии, были определены основные требования для выращивания чайных плантаций, создана база данных водно-артериальной, климатической зоны, геофизические показатели почвы выгодных для посадки чайных плантаций в других регионах Азербайджана. На основе исследований в области мелиорации и агротехники чайных плантаций была предложена модель по выбору метода полива чайных плантаций с применением экспертного обоснования и математического моделирования. Для организации процесса выбора сорта чая, территории для посадки и выращивания чая, организации агротехнических и поливных операций, сбора и учета чайных сортов, предложена блок-схема функционирования интерфейса интеллектуальной ирригационной информационной системы.

Ключевые слова: чайная плантация, интеллектуальная информационная система полива, выращивание чая, автоматизация мелиорации, агротехнические работы, предгорные регионы.
\end{abstract}

\section{ВВЕДЕНИЕ}

Экономическое развитие страны зависит от планомерного, рационального использования природных, сельскохозяйственных ресурсов и комплексного внедрения современных

Попова Ольга Ивановна e-mail: olga_10_popova@mail.ru достижений компьютерных и информационных технологий. Одним из областей сельского хозяйства где ручной труд является основополагающей можно считать чаеводство. На широких субтропических низменных, предгорных просторах чаеводческих стран Индии, Китая, Шри Ланки, России и других регионах преобладают традиционные технологии механизации, мелиорации, что существенным

Контент доступен под лицензией Creative Commons Attribution 4.0 License.

The content is available under Creative Commons Attribution 4.0 License. 
Разработка интеллектуальной инбормационной системы для выращивания чайных плантаций ...

образом влияет на снижение производительности и качества чайных плантаций.

Как известно выращивание и уход за чаем - это долгий и сложный агротехнический и мелиорационный процесс $[1,2]$. Чайные плантации, выращиваемые в течение 50-60 лет, требуют эффективной агротехнической работы и своевременный полив посевных площадей. В настоящее время для улучшения качества и производительности чая проводятся исследовательские работы по эффективному использованию водных ресурсов этих регионов, выбору видов полива чайных листьев, анализу и учету метеорологических и геофизических условий этих районов. Однако анализ данных по выращиванию чайных плантаций в постсоветских странах (Россия и Азербайджан) [3-5] показывает, что недостаточное использование современных достижений компьютерной техники и информационных технологий должным образом не обеспечивают решение вопроса по улучшению качества листьев чайных плантаций, эффективному использованию водных ресурсов и повышения производительности чайных плантаций предгорных регионах.

Эффективное применение последних достижений компьютерной техники и информационных технологий, информационно-измерительных и интеллектуально - управляющих систем в процессе выращивания чайных плантаций предгорных субтропических регионах позволило бы решить поставленные задачи по обеспечению высокой производительности и улучшению качества чайных плантаций, а также выхода пучших сортов чая постсоветских стран на мировой чайный рынок $[6,7]$.

В этой связи, определена цель статьи, предусматривающая создание интеллектуальной информационной системы контроля и управления процессом выращивания чайной плантации, а также обеспечивающий эффективное использование водных ресурсов, выбор видов полива чайных кустов и автоматизацию процесса мелиорации и агротехнических работ в зависимости от метеорологических, геофизических и биологических данных чайного растения. В соответствии с целью данной статьи требуется решение следующих задач:

1. Определение основных метеорологических, геофизических требований для автоматизации процесса выращивания чайных плантаций на основе сравнительного анализа и оценки состояния мировых производителей в этой области сельского хозяйства.

2. Создание интеллектуальной автоматизированной системы управления и контроля для выращивания чайной плантации и разработка схемы ее функционирования.

3. Выбор информационно-измерительных средств и разработка программных модулей для обеспечения автоматизации контроля и управления процессом полива чайной плантации в зависимости от метеорологических показателей окружающей среды и геофизических параметров почвы.

4. Создание системы управления базой данных для автоматизации процесса агротехнических работ, необходимых для обеспечения высокого качества выращивания и высокой производительности чая;

5. Разработка алгоритма управления и программного обеспечения для автоматизированной системы управления эффективного водоснабжения чайной плантации с проведением компьютерных экспериментов.

\section{1. МАТЕРИАЛЫ И МЕТОДЫ}

Создание интеллектуальной автоматизированной системы управления и контроля для выращивания чайной плантации и разработка ее структуры. Из анализа мирового опыта процесса выращивания чайных плантаций [8-10] было установлено, что для их выращивания требуются следующие условия:

1. Субтропические метеорологические условия:

1.1. Весной, летом и осенью среднесуточная температура должна составлять $20^{\circ} \mathrm{C}$.

1.2. Зимой средняя дневная температура может варьироваться от $-3^{\circ}$ до $10^{\circ} \mathrm{C}$.

1.3. Яркие и солнечные дни должны быть достаточно длинными, чтобы усилить ароматические свойства чайных листьев. 
Д. Ф. оглу Мамедов, Р. О. гызы Нариманова, Г. Ю. гъззы Аббасова, О. И. Попова, М. И. Попова

2. Геофизические условия:

2.1. Почва должна быть влажной и хорошо дренированной.

2.2. Почва должна быть достаточно мягкой, легкой и в то же время слегка кислой. Часто чайные плантации высаживаются в неровных частях гор для обеспечения оптимального дренажа почвы.

На примере субтропического региона Азербайджана проведем анализ статистического температурного режима каждого месяца в Ленкаране, необходимого для выращивания чайных кустов в этом регионе [11]. Для этого построим таблицу с представлением среднемесячной температуры для обеспечения эффективного выращивания чайной плантации (табл. 1).

Анализ статистических метеорологических параметров чайных регионов Индии [9, 10] показывает, что, в отличие от Ленкоранской зоны, в других районах метеорологические данные превышают нормы. Статистические метеоданные территорий стран-производителей чая представлены на рис. 1.

Как видно из рис. 1, основной причиной низкой продуктивности чайных плантаций в Ленкаране является небольшое количество осадков в апреле, мае и летом (особенно но-

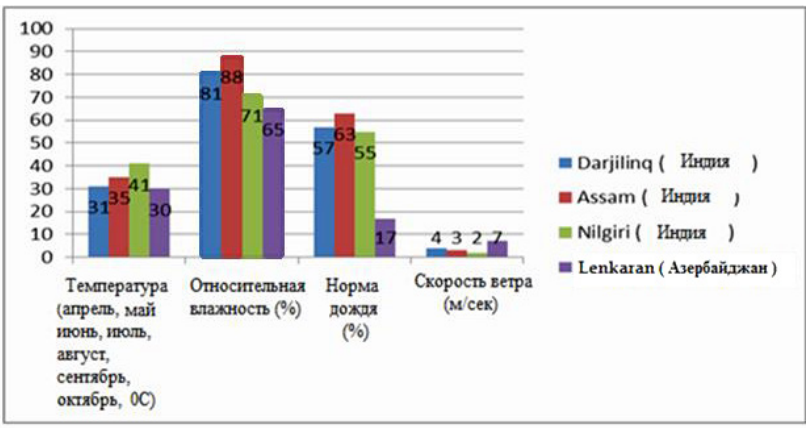

Рис. 1. Сравнительная диаграмма средних статистических метеорологических данных мировых производителей (Индии) и Ленкорани (Азербайджана)

[Fig. 1. Comparative chart of the average statistical meteorological data of world producers (India) and Lenkran (Azerbaijan)]

чью и утром). В этих районах чайные плантации в основном высаживаются на равнинах или в районах с низким наклоном. Кроме того, существующие ирригационные системы чайных плантаций в Ленкаране не достаточно отвечают требованиям полива [12].

В ведущих странах-производителях чайные плантации в основном выращиваются в районах с неровной местностью. Например, в Индии, Муннаре и Шри-Ланке чайные плантации сажают под углом 30-45, а чай собирают традиционным способом каждую весной,

Таблица 1. Средняя месячная температура для выращивания чая Table 1. Average monthly temperature for growing tea

\begin{tabular}{|l|c|c|c|}
\hline $\begin{array}{c}\text { Статистическая } \\
\text { в Ленкаране }\end{array}$ & $\begin{array}{c}\text { Нижняя } \\
\text { температура, }{ }^{\circ} \mathrm{C}\end{array}$ & $\begin{array}{c}\text { Верхняя } \\
\text { температура, }{ }^{\circ} \mathrm{C}\end{array}$ & $\begin{array}{c}\text { Оптимальная } \\
\text { температура для } \\
\text { роста чайных кустов }\end{array}$ \\
\hline Декабрь & 3 & 10 & 7 \\
\hline Январь & 0 & 7 & 7 \\
\hline Февраль & 1 & 7 & 7 \\
\hline Март & 4 & 11 & 14 \\
\hline Апрель & 9 & 18 & 20 \\
\hline Май & 13 & 23 & 20 \\
\hline Июнь & 18 & 27 & 20 \\
\hline Июль & 20 & 30 & 20 \\
\hline Август & 20 & 30 & 20 \\
\hline Сентябрь & 17 & 26 & 20 \\
\hline Октябрь & 12 & 20 & 16 \\
\hline Ноябрь & 7 & 14 & \\
\hline
\end{tabular}


Разработка интеллектуальной инбормационной системы для выращивания чайных плантаций ...

летом и осенью. На чайных плантациях, построенных по этому принципу, скорость ветра уменьшается, обеспечивается нормальный водный баланс, необходимый для корней чайных кустарников, а тропические дожди в предгорьях ранним утром обеспечивают $80-85 \%$ влажности чайных участков [13]. Это, в свою очередь, повышает производительность чайных плантаций и качество чая в этих районах.

Чтобы повысить урожайность и качество чая на чайных плантациях Ленкаранского района, очень важно создать многофункциональную ирригационную систему (полив чайных листьев и корней чайных кустов), а также обеспечивать посадку чайных кустов на предгорной местности и интеллектуальную систему полива.

При этом основными вопросами исследований на начальном этапе являются анализ существующих площадей и правил посадки чайных плантаций в Ленкаранской зоне, обеспечение надежной системы водоснабжения, выбор методов полива.

Анализ используемого принципа посадки чайных плантаций в Ленкаранской зоне показывает, что 80 \% чайных плантаций посажены на равнинных местах. Продуктивность таких чайных плантаций оценивается в 50-60 лет. В районах, используемых для орошения, оптимальный уклон должен составлять 0,1-0,5\%. Если уклон меньше 0,05 \%, полив невозможен из-за отсутствия естественного стока воды. Если уклон колеблется между 1-2 \%, орошаемые почвы могут быть лишены плодородного слоя из-за мытья поверхности.

При организации агротехнических работ на чайных плантациях следует учитывать, что частая обработка почвы и минеральное удобрение оказывают негативное влияние на качество чая. Разумеется, применение минеральных удобрений в сочетании с другими агротехническими мероприятиями повышает производительность чая, но в то же время снижает аромат, плотность и качество чая в целом. В Индии, например, даже чайные плантации не культивируются, то есть естественному развитию чайного куста не мешают. Этот принцип оказывает существенное положительное влияние на развитие чайного куста. Поскольку чайные кусты необходимо омолаживать каждые 20-25 лет, то на плантациях должны проводиться отдельные агротехнические работы, такие как обрезка некоторых кустов чая.

\section{РЕЗУЛЬТАТЫ И ИХ ОБСУЖДЕНИЕ}

Разработка базы знаний по выращиванию чайных плантаций предгорной территории Азербайджана. В соответствии с методами посадки чайных плантаций на неровных участках мировых чайных производителей, рассмотрим вопрос по выбору и созданию новых чайных плантаций в других регионах Азербайджанской Республики со схожими климатическими условиями, выгодными геофизическими показателями почвы и удобными ресурсами водоснабжения. Основные требования для выращивания качественных чайных плантаций должны соответствовать следующим условиям:

- выбранная неровная рельефная зона должна быть рядом с источником воды;

- неровная местность должна быть 12001500 метров над уровнем моря;

- площадь чайной плантации должна составлять 45-100 га;

- чайная плантация, посаженная в выбранной неровной местности, должна быть защищена от холодных ветров;

- угол наклона неровного рельефа, предназначенного для чайной плантации, должен составлять $30-45^{\circ}$;

Согласно исследованиям, проведенным в соответствии с зонами климатической карты Азербайджанской Республики, было установлено, что климат, соответствующий климату Ленкорани имеется также в Гусарском, Губинском, Закатальском и Шекинском районах [11]. Климат этих районов умеренный с необходимым распределением осадков. Эти регионы типичны для горнолесной зоны на южном (600-1500 м.) и северо-восточном (200500 м.) склонам Большого Кавказа. Годовое количество осадков в этих зонах составляет 75-100 \% от возможного испарения на южном склоне и 50-100 \% на северо-восточном склоне. Зимы мягкие, а лето теплое. 
На рис. 2 показаны районы Азербайджана, пригодные для посадки чайных плантаций.

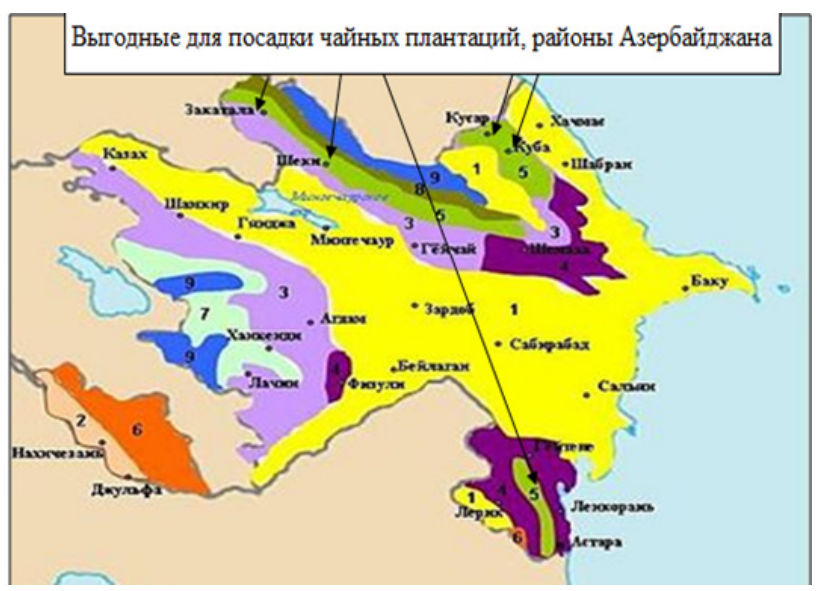

Рис. 2. Схема выгодных районов для посадки чайных плантаиий в Азербайджане

[Fig. 2. Scheme of favorable areas for planting tea plantations in Azerbaijan]

Рельефно-климатическая и геофизическая база данных территорий, выгодных для посадки чайных плантаций в Азербайджане была создана на основе следующих рельефных, метеорологических показателей в «равномерно распределенных умеренно-теплых» климатических зонах Азербайджана (табл. 2). Рельефы этих районов соответствуют север- ным и западным регионам гор Большого Кавказа, начинающиеся от предгорий Главного Кавказского хребта.

Для обеспечения эффективного выбора территории по посадке и выращиванию чайных плантаций в Азербайджане предлагается создать экспертную систему «Рельефно-климатическая и геофизическая база данных территорий для посадки и выращивания чайных плантаций в Азербайджане» включены следующие данные:

1. Название района (Район_наименование);

2. Координаты положения региона $\left(R G N_{r i} \rightarrow X_{r i}, Y_{r i}, Z_{r i}\right)$;

3. Наименование и координаты местоположения района, отведенного для чайной плантации в районе $\left(R Y N_{n i} \rightarrow X_{n i}, Y_{n i}, Z_{n i}\right)$;

4. Рельефная структура участка, отведенного под чайные плантации в округе $R F S_{s} \rightarrow$ площадь участка $-S_{y y \cdot i}\left(m^{2}\right)$; угол наклона $\alpha_{y 4}\left({ }^{\circ}\right)$

5. Температура региона, отведенного под чайную плантацию $\left(T_{\text {рег }}\right)$ :

5.1. Минимальные и максимальные температуры района зимой, отведенного для чайных плантаций в регионе $\left(\right.$ мин $\left(T_{\text {зим }}\right)$, макс $\left.\left(T_{\text {зим }}\right)\right)$;

Таблииа 2. Водно-артериальная, климатическая база данных территорий, выгодных для посадки чайных плантаций в Азербайджане [Table 2. Water-arterial, climate database of territories favorable for planting tea plantations in Azerbaijan]

\begin{tabular}{|c|c|c|c|c|c|c|c|c|}
\hline \multirow[b]{2}{*}{ Район } & \multirow[b]{2}{*}{$\begin{array}{c}\text { Водоснаб- } \\
\text { жение } \\
\text { (река) }\end{array}$} & \multirow{2}{*}{$\begin{array}{c}\text { Годовое } \\
\text { коли- } \\
\text { чество } \\
\text { осадков } \\
\text { (мм) }\end{array}$} & \multicolumn{3}{|c|}{ Температура воздуха $\left({ }^{\circ} \mathrm{C}\right)$} & \multirow{2}{*}{$\begin{array}{c}\text { Скорость } \\
\text { ветра } \\
\text { макси- } \\
\text { мальная } \\
(\mathrm{M} / \mathrm{c})\end{array}$} & \multirow[b]{2}{*}{$\begin{array}{c}\text { Направ- } \\
\text { ления } \\
\text { ветра }\end{array}$} & \multirow{2}{*}{$\begin{array}{c}\text { Относи- } \\
\text { тельная } \\
\text { влаж- } \\
\text { ность (\%) }\end{array}$} \\
\hline & & & весна & лето & осень & & & \\
\hline Гусар & $\begin{array}{l}\text { Самур- } \\
\text { Абшерон } \\
\text { канал, } \\
\text { Гусарчай }\end{array}$ & $350-1500$ & $10-15$ & $24-32$ & $7-14$ & 13 & $\begin{array}{l}\text { Юго-вос- } \\
\text { точный }\end{array}$ & 89 \\
\hline Губа & $\begin{array}{l}\text { Гудял, } \\
\text { Карачай, } \\
\text { Вальвала }\end{array}$ & $500-900$ & $5-10$ & $20-25$ & $6-10$ & 9 & $\begin{array}{l}\text { Северо- } \\
\text { восточ- } \\
\text { ный }\end{array}$ & 85 \\
\hline $\begin{array}{l}\text { Зака- } \\
\text { тала }\end{array}$ & Тала & $600-1600$ & $6-21$ & $24-30$ & $4-12$ & 12 & $\begin{array}{l}\text { Юго-за- } \\
\text { падный }\end{array}$ & 75 \\
\hline Шеки & Киш & $775-1100$ & $6-18$ & $20-25$ & $3-9$ & 15 & $\begin{array}{l}\text { Циклон- } \\
\text { ный }\end{array}$ & 88 \\
\hline
\end{tabular}


Разработка интеллектуальной инбормационной системы для выращивания чайных плантаций ...

5.2. Минимальные и максимальные весенние температуры (мин $\left(T_{\text {вес }}\right)$, макс $\left.\left(T_{\text {вес }}\right)\right)$ участка, отведенной для чайных плантаций в районе;

5.3. Минимальные и максимальные летние температуры района, отведенного для чайных плантаций в регионе (мин $\left(T_{\text {лет }}\right)$, макс $\left.\left(T_{\text {лет }}\right)\right)$;

5.4. Минимальные и максимальные температуры района, отведенного для чайных плантаций в регионе осенью (мин $\left(T_{\text {оснь }}\right)$, макс $\left.\left(T_{\text {осень }}\right)\right)$;

6. Относительная влажность участка, отведенного под чайные плантации в районе (сезон $O B_{\text {сезон): }}$ )

6.1. Минимальная и максимальная относительная влажность участка, отведенного для чайных плантаций в районе зимой (мин $\left(O B_{\text {зим }}\right)$, макс $\left.\left(O B_{\text {зим }}\right)\right)$.

6.2. Минимальная и максимальная относительная влажность участка, отведенного для чайных плантаций в районе весной $\left(\right.$ мин $\left(O B_{\text {вec }}\right)$, макс $\left.\left(O B_{\text {вec }}\right)\right)$;

6.3. Минимальная и максимальная относительная влажность в районе, выделенном для чайных плантаций в районе летом (мин $\left(O B_{\text {лет }}\right)$, макс $\left.\left(O B_{\text {rem }}\right)\right)$;

6.4. Минимальная и максимальная относительная влажность участка, отведенного для чайных плантаций в районе осенью (мин $\left(O B_{\text {осень }}\right)$, макс $\left.\left(O B_{\text {осень }}\right)\right)$;

7. Скорость ветра в районе, выделенном для чайных плантаций в районе $\left(C B_{\text {сззн }}\right)$ :

7.1. Минимальная и максимальная скорость ветра зимой в районе, отведенном для чайных плантаций в районе (мин $\left(C B_{\text {зим }}\right)$, макс $\left.\left(C B_{\text {зим }}\right)\right)$;

7.2. Минмальная и максимальная скорость ветра весной в районе, выделенном для чайных плантаций в регионе (мин $\left(C B_{\theta e c}\right)$, макс $\left.\left(C B_{\text {вec }}\right)\right)$;

7.3. Минимальная и максимальная скорость ветра летом в районе, отведенном для чайных плантаций в регионе (мин $\left(C B_{\text {лет }}\right)$, макс $\left.\left(C B_{\text {rem }}\right)\right)$;

7.4. Минимальная и максимальная скорость ветра осенью (мин $\left(C B_{\text {осень }}\right)$, макс $\left.\left(C B_{\text {оснн }}\right)\right)$ в районе, выделенном для чайных плантаций в регионе.

8. Вид земельной почвы $\left(3 \Pi_{i}\right)$, выделенного для чайной плантации в районе:

9. Солнечное время суток в округе $\left(C B_{\text {окр }}\right)$.
10. Минимальное и максимальное количество осадков в регионе $\left(\mathrm{KO}_{\text {сезон_}}\right)$.

10.1. Минимальное и максимальное годовое количество осадков зимой в районе, выделенном для чайных плантаций в округе (мин $\left(K O_{\text {зим }}\right)$, макс $\left.\left(K O_{\text {зим }}\right)\right)$;

10,2. Минимальное и максимальное годовое количество осадков весной в районе, выделенном для чайных плантаций в районе (мин $\left(K O_{\text {вес }}\right)$, макс $\left(K O_{\text {вес }}\right)$ );

10.3. Минимальное и максимальное годовое количество осадков летом в районе, выделенном для чайных плантаций в районе $\left(\right.$ мин $\left(K O_{\text {лето }}\right)$, макс $\left.\left(K O_{\text {лето }}\right)\right)$;

10.4. Минимальное и максимального годовое количество осадков осенью (мин $\left(K O_{\text {осень }}\right)$, макс $\left.\left(K O_{\text {осень }}\right)\right)$ в районе, выделенном для чайных плантаций в районе.

На основании вышеописанных разделов 1-10 создается база данных в виде диаграмм (рис. 4a, 46, 4в, 4г). При этом, выбранные предполагаемые районы для выращивания чайных плантаций, имеют характеристики, которые также вводятся в эту базу данных:

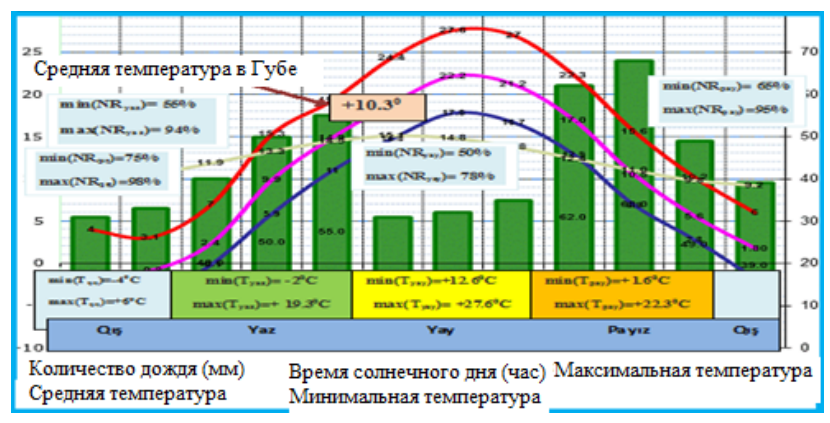
$a(a)$

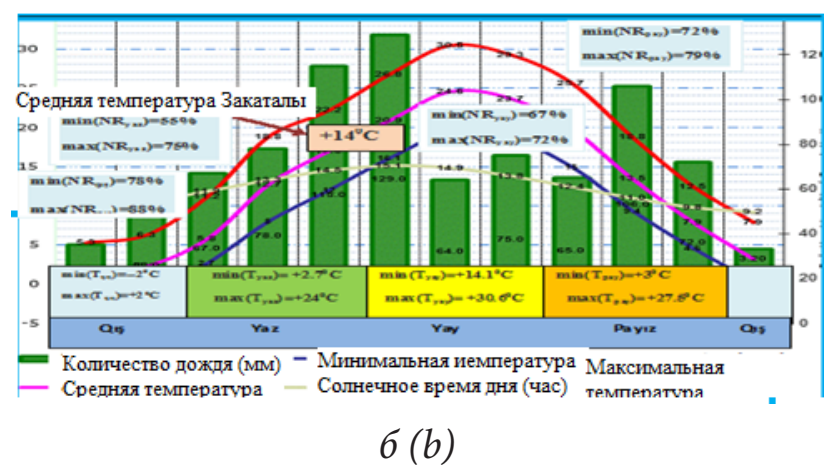




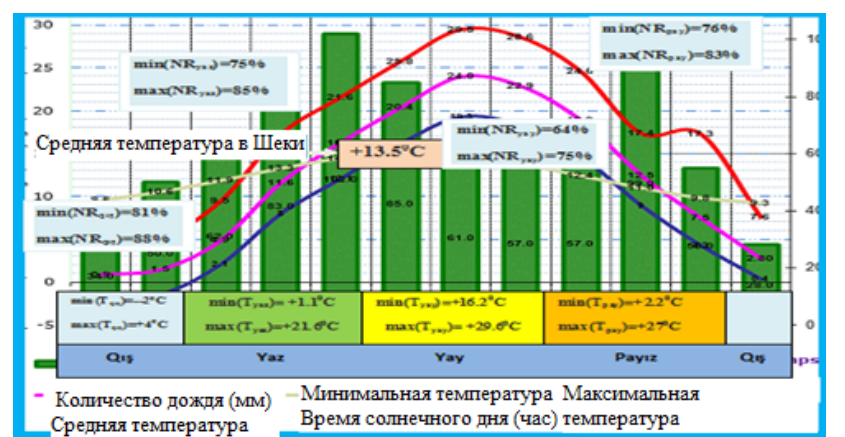

B (c)

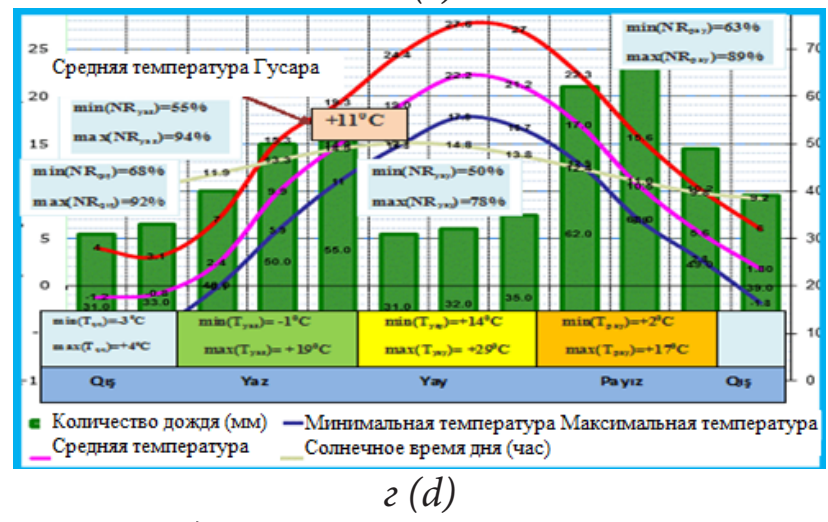

Рис. 3. Годовые климатические показатели: a-Губинского района; 6 - Закатальского района; в - Шекинского района; г - Гусарского района

[Fig. 3. Annual climate indicators: $a-$ Guba district; $b$ - Zakatala district; $c$-Sheki district; $d$ - Gusar district]

Губа размещена в регионе с координатами $41^{\circ} 22^{\prime} \mathrm{N}, 48030$ 'Е, высота - 552 м выше уровня моря. Губа имеет влажный субтропический климат. Климат Губы, в отличие от сухой погоды, мягкий и постоянно влажный. Летом погода неустойчивая, часто бывают удары молнии. Зимний сезон мягкий. Среднегодовая температура составляет $+10,3^{\circ} \mathrm{C}$.

Закатала размещена в регионе с координатами $41^{\circ} 39^{\prime} \mathrm{N}, 46038^{\prime} \mathrm{E}$, высота - 1608 м выше уровня моря. Закатала имеет влажный субтропический климат. Климат Закаталы, в отличие от сухой погоды, мягкий и постоянно влажный. Лето очень жаркое и дождливое, но часто бывают удары молнии. Зимний сезон мягкий.

Гусар размещен в регионе с координатами $41^{\circ} 25^{\prime} 38^{\prime \prime} \mathrm{N}, 48025^{\prime} 44^{\prime \prime}$, высота - 671 м выше уровня моря. Гусар имеет влажный субтропический климат. Климат Губы соответствует умеренной температуре и относительной влажности. Среднегодовая температура составляет $+11^{\circ} \mathrm{C}$.

Шеки размещен в регионе с координатами $41^{\circ} 11^{\prime} 30^{\prime \prime} \mathrm{N}, 47^{\circ} 10^{\prime} 14^{\prime \prime} \mathrm{E}$, высота над уровнем моря - 549 м. Шеки имеет влажный субтропический климат. Климат Шеки определяют циклоны и антициклоны, различные воздушные массы и местные ветра. Среднегодовая температура составляет $+12^{\circ} \mathrm{C}$.

В результате проведенного анализа основных методов и инновационных технологий в области агротехнических работ, полива и сбора урожая в процессе выращивания чая, было определено, что вопросы выращивания качественных чайных плантаций, их посадки на склонах горных районов, своевременной обрезки чайных кустарников зависят от своевременного обеспечения природными минералами, водного баланса посадочной площади, сбора и учета различных сортов чайных листьев.

При этом процесс сборки чайных листьев усложняется. В связи с этим, в зависимости от типа чайного куста, в базу данных вводятся данные, характеризующие размеры зеленых листьев в виде эллипса или круглой формы, количество и размер белых цветков, а также размер ягод чайных кустов.

Для обеспечения своевременных мелиорационных и агротехнических работ, используя знания экспертных данных по сезонному проведению агротехнических работ, требования по выполнению, используемым средствам, по применению автоматизированной системы полива, контролю биологических характеристик чайных листьев, сбору и учету качественных чайных листьев с плантаций.

В этой связи, рассмотрим вопрос создания алгоритма по выбору метода полива чайных плантаций. При этом выберем лингвистические термины в виде «Среднегодовые климатические показатели», «Текущие метеорологические показатели» и «Требуемые метеорологические характеристики» как $I_{i}, C_{i}$, $T_{i}$ (где $i=\overline{1,5}$ ). Соответственно параметры «Температура воздуха - $T h_{j}$, «Относительная влажность - $R n_{j}$, «Осадки - $M y_{j}$ ", «Скорость ветра - $S k_{j}$ » и «Солнечные дни $I V g_{j}$ в в зависимости от порядкового номера 
Разработка интеллектуальной инбормационной системы для выращивания чайных плантаций ...

региона и чайной плантации выражается следующей логической формулой:

$$
N R_{\text {чn }} \rightarrow\left\{\begin{array}{l}
\forall \dot{Y}_{i} \in\left(T h_{j}, R n_{j}, M y_{j}, S k_{j}, I V g_{j}\right) ; \\
\forall C_{i} \in\left(T h_{j}, R n_{j}, M y_{j}, S k_{j}, I V g_{j}\right) ; \\
\forall T_{i} \in\left(T h_{j}, R n_{j}, M y_{j}, S k_{j}, I V g_{j}\right) .
\end{array}\right.
$$

Метод полива выбирается в зависимости от среднего климата региона, текущих метеорологических показателей и метеорологических показателей, необходимых для выращивания и сбора чайных плантаций в этом регионе. Например, если показатели $C_{i}\left(R n_{j}\right)$, $T_{i}\left(R n_{j}\right)$ низкие в регионе, то выбирается метод аэрозольного полива листьев чайной плантации.

В этом случае логическое выражение записывается следующим образом:

$$
\left(C_{i}\left(R_{n j}\right)<<T_{i}\left(R_{n j}\right)\right) \rightarrow
$$

(Метод поли - распьлительной $\left(S_{s}\right)$ ),

где время распылительного полива $S_{s}$ должно быть доведено до значения $T_{i}\left(R n_{j}\right)$. Для этого необходимо искусственно увеличить относительную влажность воздуха, которая обеспечивало бы влажность листьев чайного куста. Например, в Закатальском районе 01.08.2019 г. относительная влажность составляла $C_{i}\left(R_{n i}\right)=52 \%,\left(T_{i}\left(R_{n i}\right)=78 \%\right)$. При этом дополнительно требуется аэрозольное орошение на чайных плантациях для увеличения относительной влажности листьев чайной плантации.

Из анализа статистических данных средняя температура воздуха на 01.08.2019 г. Составлял $T_{h} \approx 25^{\circ} \mathrm{C}$. Тогда функция объема $R H_{\text {chky }}$ влажности для листьев чайного куста принимается 0,03. При этом выполняется условие $0<R H_{c h k y}<1,0$, т. к. когда $R H_{c h k y}$ принимается слишком малым, то погрешность влажности также уменьшается. Если значение RH больше 0,5, то погрешность влажности составляет $T_{s h}= \pm 1,0^{\circ} \mathrm{C}$.

В этом случае значение точки росы для листьев чайных плантаций определяется следующим образом:

$$
T_{s} \approx T_{h}-\frac{1-R H_{c k y}}{0,05} \approx 19,4{ }^{\circ} \mathrm{C} .
$$

Значение относительной влажности воздушно-водной массы для листьев чайной плантации на 01.08.2019 г. определяется по следующей формуле:

$$
R_{h s}=\frac{T_{s}}{T_{h}} \times 100 \%=77,6 \% .
$$

Тогда $R_{h s} \approx T\left(R_{n}\right)$.

Поскольку определенное значение $R_{h s}$ и требуемая относительная влажность приблизительно $T_{i}\left(R_{n i}\right) \approx 78 \%$, то фракция объема листьев чайного куста $\left(R H_{\text {chky }}=0,03 R\right)$ была выбрана правильно. Значения выше или ниже нормативной влажности $R H_{\text {chky }}$ не соответствуют требуемой относительной влажности $\left(T_{i}\left(R_{n i}\right) \approx 78 \%\right)$.

Одним из важных вопросов эффективного выращивания чайных плантаций является обеспечение необходимого водного баланса корней чайных кустов. Для этого следует выбрать метод дождевого орошения чайной плантации, поскольку необходимый водный баланс в корневой части чайного куста формируется довольно быстро и соответственно при этом расход воды уменьшается. Необходимый водный баланс на земельном участке чайной плантации определяется по следующей формуле:

$$
V_{C P}=\frac{R^{3}}{h_{R}^{3}-R^{3}} \times 100
$$

где $R-$ питаемая водой часть почвы в речной плантации (мм); $h_{r}-$ площадь суши (мм), где вода поступает в чайные плантации; $V_{C P}$ - относительная влажность (\%).

Потребление воды в оросительной системе методом дождевого полива определяется на основе необходимого водного баланса $V_{C P}$ чайной плантации. Другим параметром, влияющим на этот показатель, является время удерживания корня влаги чайного куста. Как известно, влага в корне чайного куста должна оставаться недолго, поскольку избыточная влажность приводит к биологическому разрушению чайного куста. Контроллер управления и передатчик, регистрирующий влажность почвы, установлены в автоматизированной ирригационной системе, чтобы обеспечить требуемое содержание влаги на участке почвы русла реки.

Организация процесса эффективного выращивания чайных кустов между информа- 
Д. Ф. оглу Мамедов, Р. О. гызы Нариманова, Г. Ю. гызы Аббасова, О. И. Попова, М. И. Попова

ционной и технической поддержкой системы полива обеспечивается интерфейсом. На этом уровне также используются автоматизированное рабочее место оператора, автоматизированная система полива, агротехническая система управления, локальная и глобальная сетевая система беспроводной связи.

Для организации процесса эффективного выращивания чайных кустов рассмотрим сорта чая мировых производителей, процесс их посадки, выращивания при горной территории, организацию агротехнических работ с применением технологии автоматизации, выбора вида полива в зависимости от метеорологических и геофизических показателей выбранного региона.

Проведенный анализ показывает, что существующие показатели климата и рельефа для выращивания черного чая в провинциях Дарджилинг, Лапсанг, Сушонг, Ассам и Кимун соответствуют показателям зон Закатала, Гусар, Губа и Шеки Азербайджана.

Метеорологические показатели для выращивания черного чая в провинции Лапсанг Сушонг: Средняя температура $+20-23{ }^{\circ} \mathrm{C}$; минимальная относительная влажность $-70 \%$; максимальная относительная влажность $85 \%$. Высота над уровнем моря - 1000-1300 м.

Метеорологические показатели выращивания черного чая в провинции Дян Хун: Средняя температура $+15-18{ }^{\circ} \mathrm{C}$; минимальная относительная влажность - $65 \%$; максимальная относительная влажность - $81 \%$. Высота над уровнем моря - 1000-2000 м.

Существующие метрологические показатели выращивания черного чая в провинции Кимун: Средняя температура $-+15-25^{\circ} \mathrm{C}$; минимальная относительная влажность $75 \%$, максимальная относительная влажность - 95 \%. Высота над уровнем моря $850-1100 \mathrm{M}$.

Существующие метрологические показатели выращивания черного чая в провинции Дарджилинг: Климат муссонный. Максимальная средняя температура $-+15^{\circ} \mathrm{C}$, минимальная средняя температура $-+8{ }^{\circ} \mathrm{C}$; минимальная относительная влажность - $70 \%$, максимальная относительная влажность 95 \%. Высота над уровнем моря - 2134 м.
Метеорологические показатели выращивания черного чая в Ассаме соответствуют нижеследующим параметрам: - тропический муссонный климат;

- максимальная температура весной, летом и осенью $-+35-38^{\circ} \mathrm{C}$, минимальная температура зимой $+6-8{ }^{\circ} \mathrm{C}$;

- минимальная относительная влажность - 35 \% (летом), максимальная относительная влажность - 92 \% (осенью и зимой);

- высота над уровнем моря - 1500-2000 м.

Организация процесса выбора сорта чая, территории для посадки и выращивания чая, организации агротехнических и поливных операций, сбора и учета чайных сортов представляется в виде блок-схемы функционирования интерфейса интеллектуальной ирригационной информационной системы (рис. 4).

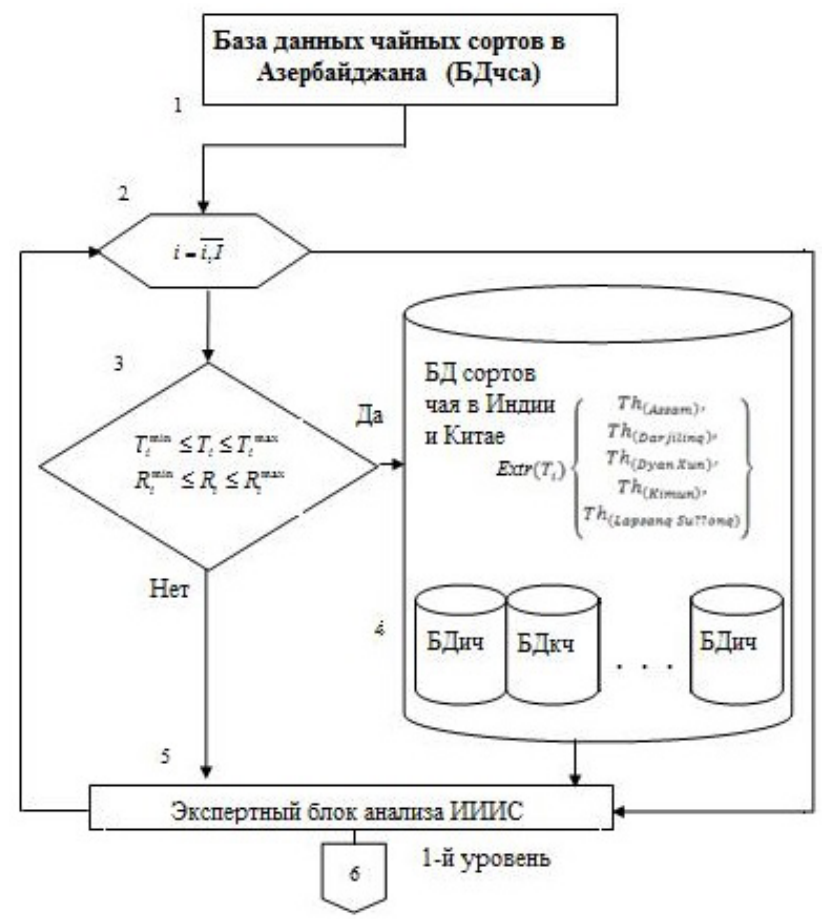

Рис. 4. Блок-схема функиионирования ИИИС, обеспечивающая процесс выращцвания чайной плантации

[Fig. 4. Block diagram of the functioning of the AIIS, which provides the process of growing a tea plantation] 
Разработка интеллектуальной информационной системы для выращивания чайных плантаций ...

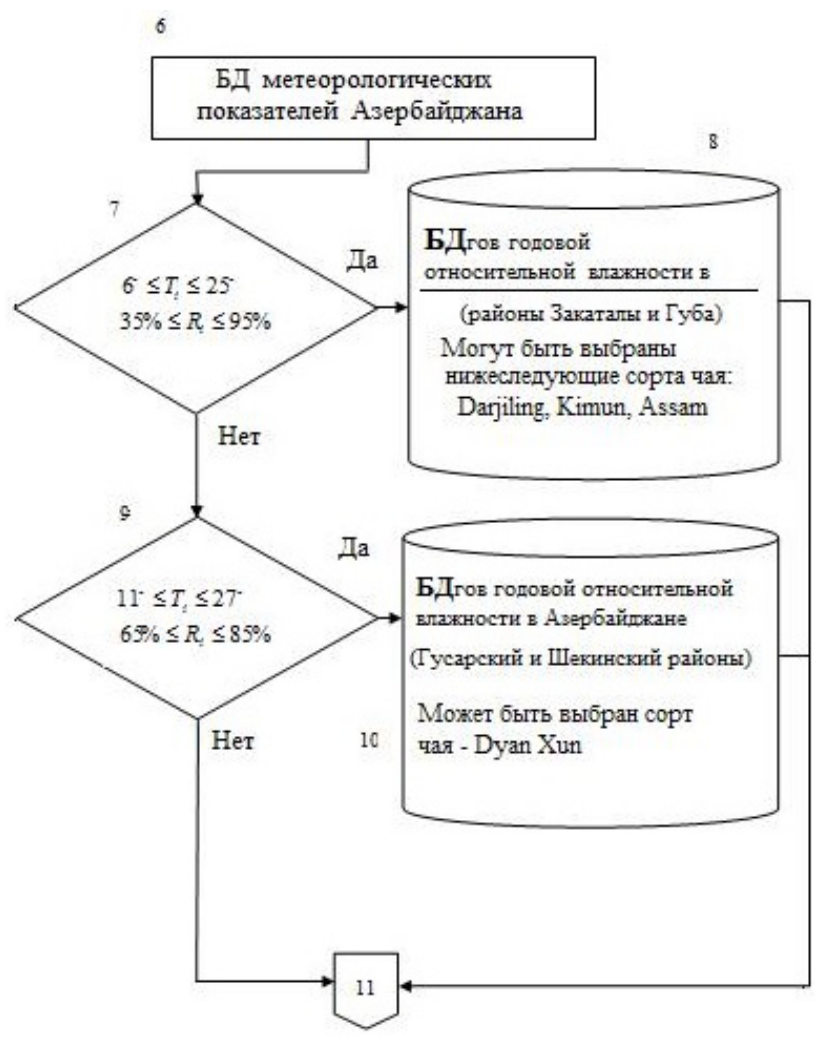

11

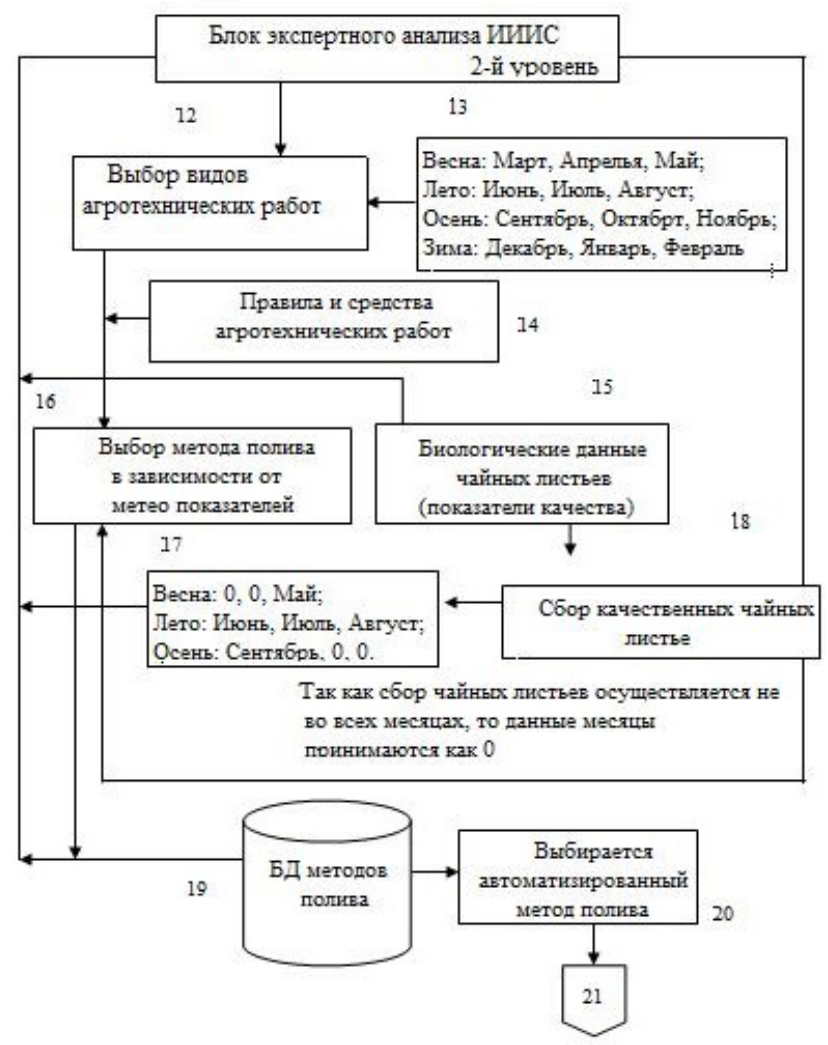

Продолжение рис. 4

[Continuation of Fig. 4]

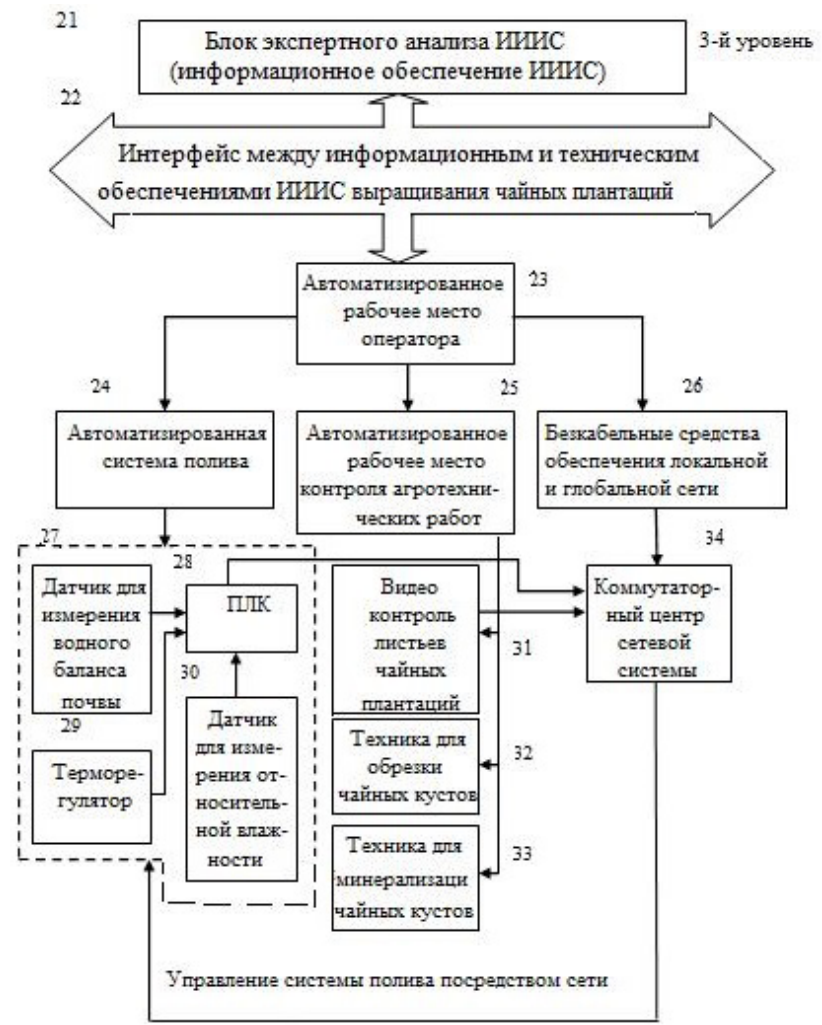

Продолжение рис. 4

[Continuation of Fig. 4]

\section{ЗАКЛЮЧЕНИЕ}

В результате проведенного сравнительного анализа проблемы и исследованиям по разработке интеллектуальных информационных систем для выращивания сельскохозяйственных растений (на примере чайных плантаций), можно сделать вывод:

Проведя сравнительный анализ статистических метеорологических данных мировых производителей чая Азербайджана, была построена сравнительная диаграмма средних метеорологических показателей этих стран и определены основные требования необходимых показателей температуры, относительной влажности воздуха, солнечных дней, скорости ветра для выращивания чайных плантаций, что способствовало бы повышению производительности и качеству чайных листьев.

В соответствии с методами посадки чайных плантаций на неровных участках мировых чайных производителей на примере Индии, были определены основные требования 
для выращивания чайных плантаций, создана база данных водно-артериальной, климатической зоны, геофизические показатели почвы выгодных для посадки чайных плантаций в других регионах Азербайджана.

На основе исследований в области мелиорации и агротехники чайных плантаций была предложена модель по выбору методу полива чайных плантаций с применением экспертного обоснования и математического моделирования.

Для организации процесса выбора сорта чая, территории для посадки и выращивания чая, организации агротехнических и поливных операций, сбора и учета чайных сортов, предложена блок-схема функционирования интерфейса интеллектуальной ирригационной информационной системы

\section{КОНФЛИКТ ИНТЕРЕСОВ}

Авторы декларируют отсутствие явных и потенциальных конфликтов интересов, связанных с публикацией настоящей статьи.

\section{СПИСОК ЛИТЕРАТУРЫ}

1. Ambachew Z. G. Review on integrated nutrient management of tea // Journal Cogent Food \& Agriculture. 11 nov. 2018. Web of sciences. P. 1-12.

2. Iman Haqiqi, Danielle S. Grogan, Thomas W. Hertel, and Wolfram Schlenker Quantifying the Impacts of Compound Extremes on Agriculture and Irrigation Water Demand. Hydrology Earth System Sciences. Discuss. - URL: https://doi. org/10.5194/hess-2020-275, 2020.

3. Рьндин А. В., Туов М. Т. Культивирование чая в субтропиках России // Наука Кубани. - 2006. - № 4. - С. 28-32.

4. Семёнов В. М. Азербайджанский чай // Чайные рецепты и чайные секреты / Под ред. Е. Н. Авадяева. - М. : Олма-Пресс, 2002. - 351 с.

5. Рынок чая: комплексный анализ и прогноз до 2016 года [Электронный ресурс]. URL: http://www.foodmarket.spb. ru/ marketing1.ru (дата обращения: 15.02.2016).

6. Javadi Kia P., Tabatabaee Far A., Omid M., Alimardani R. and Naderloo L. Intelligent Control
Based Fuzzy Logic for Automation of Greenhouse Irrigation System and Evaluation in Relation to Conventional Systems // World Applied Sciences Journal. - 2009. - № 6(1). - P. 16-23.

7. Стрельцов Ф. Ф. Совершенствование конструкции автоматизированных систем орошения в теплицах и повышение техники безопасности при работе с ним // Вестник Алтайского государственного аграрного университета. - 2009. - № 5. - С. 34-41.

8. Добежина С. В., Беседина Т. Д., Туов М. Т., Пчихачев Э. К. Обоснование необходимости орошения чайных плантаций в адыгее на основе оценки почвенных и климатических условий // Вестник АПК Ставрополья издательство: Ставропольский государственный аграрный университет. - 2015. - issn: 22229345. - № 4 (20). - C. 155-160 .

9. Dutta R., Stein A., Smaling M. A., Bhagat R. M., Hazarika, M. Effects of plant age and environmental and management factors on tea yield in Northeast India // Agronomy Journal. - 2010. - P. 1290-1301.

10. Wijeratne M. A., Fordham R. Effect of climatic factors on the growth of tea (Camelia sinensis L.) in the low country wet zone of Sri Lanka // Sri Lanka Journal of Tea Science. - 1996. 46. - P. 21-34.

11. Мамедов М. А., Кулиев С. А., Джафаров Б. Ш. Эффективные способы выращивания посадочного материала для закладки чайных плантаций в Азербайджане // Субтроп, культуры, IS78. - 2011. - № 3. - С. 109-116.

12. Ghuseynov E. B., Mammadov J. F., Iskenderov A. A., Abbasova G. Y. Development of complex intellectual system for efficiensy growing tee plant // International Scientific Journal Theoretical Applied and Science, p-ISSN: 2308-4944(print) e-ISSN: 2409-0085. - 2015. Iss. 08, V. 28. - P. 37-43.

13. Ghosh A, Roy R. GIS anchored integrated plantation management. Proceedings of Map India Conference, New Delhi, India. - 2004. P. 123-136. 
Разработка интеллектуальной инбормационной системы для выращивания чайных плантаций ...

Мамедов Джаваншир Фирудин оглу - д-р техн. наук, проф., зав. кафедрой «Автоматизация процессов» Сумгаитского государственного университета.

E-mail: cavan62@mail.ru

ORCID iD: https://orcid.org/0000-0002-1998-3137

Нариманова Роя Октай гызы - аспирант кафедры «Автоматизация процессов» Сумгаитского государственного университета.

E-mail: Royaoktay@bk.ru

ORCID iD: https://orcid.org/0000-0002-7814-6259

Аббасова Гюльнара Юсиф гызы - канд. техн. наук, старший преподаватель кафедры «Информатика» Сумгаитского государственного университета.

E-mail: gyulnarayusif@bk.ru

ORCID iD: https://orcid.org/0000-0001-6498-5927

Попова Ольга Ивановна - канд. техн. наук, доц., зав. каф. «Конструкторско-технологическое обеспечение нефтегазохимического машиностроения» филиал Воронежского государственного технического университета в г. Борисоглебске.

E-mail: olga_10_popova@mail.ru

ORCID iD: https://orcid.org/0000-0001-7683-8932

Попова Маргарита Ивановна - канд. техн. наук, доц. каф. «Автоматизированного оборудования машиностроительного производства» Воронежского государственного технического университета.

E-mail: vip.popovamargarita@mail.ru

ORCID iD: https://orcid.org/0000-0002-1468-398

DOI: https://doi.org/10.17308/sait.2021.1/3375

Received 19.01.2021

Accepted 26.04.2021

ISSN 1995-5499

\title{
DEVELOPMENT OF INTELLECTUAL INFORMATION SYSTEM FOR GROWING TEA PLANTATIONS IN MOUNTAIN REGIONS
}

\author{
(C) 2021 J. F. Mammadov' ${ }^{1}$ R. O. Narimanova ${ }^{1}$, G. Y. Abbasova ${ }^{1}$, O. I. Popova ${ }^{\bowtie 2}$, M. I. Popova ${ }^{2}$ \\ ${ }^{1}$ Sumgait State University \\ 1st building, 43rd quarter, Sumgait, AZ 5008 \\ ${ }^{2}$ Voronezh State Technical University \\ 84, 20 years October Street, 394006 Voronezh, Russian Federation
}

\begin{abstract}
Annotation. Based on a comparative analysis of the problem and research on the development of intelligent information systems for growing agricultural plants (using tea plantations as an example), the purpose and main issues of the article were determined. The aim of the article is to create an intelligent information system for monitoring and managing the process of growing tea plantations, ensuring the efficient use of water resources, choosing the types of irrigation of tea bushes and automating the process of land reclamation and agricultural work depending on the

e-mail: olga_10_popova@mail.ru meteorological, geophysical and biological data of the tea plant. Having carried out a comparative analysis of the statistical meteorological data
\end{abstract}

Popova Olga I. 
of the world tea producers in Azerbaijan, a comparative diagram of the average meteorological indicators of these countries was built and the basic requirements for the necessary indicators of temperature, relative humidity, sunny days, wind speed for growing tea plantations were determined, which would provide an increase in the productivity and quality of tea leaves. In accordance with the methods of planting tea plantations on uneven areas of world tea producers using the example of India, the basic requirements for the cultivation of tea plantations were determined, a database of the water-arterial, climatic zones and geophysical soil indicators suitable for planting tea plantations in other regions of Azerbaijan were created. Based on research in the field of land reclamation and agricultural technology of tea plantations, a model was proposed for choosing the method of watering tea plantations using expert substantiation and mathematical modeling. To organize the selection process of tea varieties, areas for planting and growing tea, organizing agro - technical and irrigation operations, collecting and registering tea varieties, a block diagram of the operation of the interface of the intellectual irrigation information system is proposed.

Keywords: tea plantation, intellectual information system for irrigation, tea cultivation, land reclamation automation, agricultural work, in mountainous regions.

\section{CONFLICT OF INTEREST}

The authors declare the absence of obvious and potential conflicts of interest related to the publication of this article.

\section{REFERENCES}

1. Ambachev Z. G. (2018) Review of integrated management of tea nutrients. Cogent Food \& Agriculture Magazine. November 11, 2018. Web of sciences. P. 1-12.

2. Iman Hakiki, Daniel S. Grogan, Thomas W. Hertel, and Wolfram Schlenker (2020) Quantifying the Impacts of Compound Extremes on Agriculture and Irrigation Water Demand. Hydrology Earth System Sciences. Discuss. Available at: https://doi.org/10.5194/hess-2020- 275, 2020.

3. Ryndin A. V., Tuov M. T. (2006) Tea cultivation in the subtropics of Russia // Nauka Kubani. No. 4. P. 28-32.

4. Semenov V., Azerzhansky M. (2002) Tea recipes and tea secrets / Ed. by E. N. Avdeeva. Moscow : OLMA-Press. $351 \mathrm{p}$.

5. Tea market: comprehensive analysis and forecast till 2016 [Electronic resource] Available at: http://www.foodmarket.spb. EN/ marketing1. ru (accessed: 15.02.2016).

6. Javadi Kia P., Tabatabai Headlamp A., Omid M., of Alimardani R. L. and Nazarlo (2009) Intelligent control based fuzzy logic for automation of greenhouse irrigation and evaluation in relation to conventional systems // World Applied Sciences Journal. No. 6(1). P. 16-23.
7. Streltsov F. F. (2009) Improving the design of automated irrigation systems in greenhouses and improving safety when working with it // Bulletin of the Altai State Agrarian University. No. 5. P. 34-41.

8. Dobezhina S. V., Besedina T. D., Tuov M. T., Pchikhachev E. K. (2015) Substantiation of the need for irrigation of tea plantations in Adygea on the basis of an assessment of soil and climatic conditions.: Stavropol State Agrarian University, state registration number: 2222-9345. No 4 (20). P. $155-160$.

9. Dutta R., Stein A., Smaling M. A., Bhagat R. M., Hazarika, M. (2010). Influence of plant age and environmental and management factors on tea yield in North-East India // Agronomic Journal. P. 1290-1301.

10. Wijeratne M. A. and Fordham R. (1996). Influence of climatic factors on the growth of tea (Camelia sinensis L.) in the low-lying wet zone of Sri Lanka // Sri Lankan Journal of Tea Science. 46. P. 21-34.

11. Mammadov M. A., Kuliev S. A., Dzhafarov B.S. (2011) Effective methods of growing planting material for laying tea plantations in Azerbaijan. Subtropics culture, IS78. No. 3. P. 109-116.

12. Huseynov E. B., Mammadov Zh. F., Iskenderov A. A., Abbasova G. Yu. (2015) Development of an integrated intellectual system for the effective cultivation of tee plants// International Scientific Journal of Theoretical-Applied and Scientific, p-ISSN: 2308-4944 (print) e-ISSN: 24090085. Iss. 08, Vol. 28. P. 37-43. 
Разработка интеллектуальной информационной системы для выращивания чайных плантаций ...

13. Gosh A., Roy R. (2004). GIS anchor integrated plantation management. Proceedings of the Map India Conference, New Delhi, India. P. $123-136$.

Mammadov Javanshir Firudin oglu - Doctor of Technical Sciences, Professor, Head of the Department of "Process Automation" of Sumgait State University.

E-mail: cavan62@mail.ru

ORCID iD: https://orcid.org/0000-0002-1998-3137

Narimanova Roya Oktay gizi - Post-graduate student of the Department of" Process Automation “ of Sumgait State University.

E-mail: Royaoktay@bk.ru

ORCID iD: https://orcid.org/0000-0002-7814-6259

Abbasova Gulnara Yusif gizi - Candidate of Technical Sciences, Senior Lecturer of the Department of "Informatics" of Sumgait State University.

E-mail: gyulnarayusif@bk.ru

ORCID iD: https://orcid.org/0000-0001-6498-5927

Popova Olga I. - Candidate of Technical Sciences, Associate Professor, Head of the Department "Design and Technological Support of Petrochemical Engineering" Branch of the Voronezh State Technical University in Borisoglebsk.

E-mail: olga_10_popova@mail.ru

ORCID iD: https://orcid.org/0000-0001-7683-8932

Popova Margarita I. - Candidate of Technical Sciences, Associate Professor of the Department of "Automated Equipment of Machine-Building Production" of the Voronezh State Technical University. E-mail: vip.popovamargarita@mail.ru

ORCID iD: https://orcid.org/0000-0002-1468-3987 